\title{
Originals
}

\section{Increased Kidney Size, Glomerular Filtration Rate and Renal Plasma Flow in Short-Term Insulin-Dependent Diabetics}

\author{
J. Sandahl Christiansen, J. Gammelgaard, M. Frandsen, and H.-H. Parving \\ Steno Memorial Hospital, Gentofte, Ultrasonic Laboratory, Herlev University Hospital, and Department of Clinical Physiology \\ and Department of Medicine C, Bispebjerg Hospital, Copenhagen, Denmark
}

Summary. Glomerular filtration rate (GFR), renal plasma flow (RPF) and kidney volume were measured in thirteen male subjects (mean age 30 years) with short-term insulin-dependent diabetes (mean duration of disease 2.4 years) and fourteen normal male subjects (mean age 29 years). GFR and RPF were measured by constant infusion technique using $\mathrm{I}^{125}$-iothalamate and ${ }^{131} \mathrm{I}$-hippuran. Kidney size was determined by means of ultrasound. GFR, RPF and kidney volume were increased in the diabetic patients compared to the normal controls, 144 versus $113 \mathrm{ml} /$ $\min \times 1.73 \mathrm{~m}^{2}(\mathrm{p}<0.0005), 627$ versus $523 \mathrm{ml} /$ $\min \times 1.73 \mathrm{~m}^{2}(\mathrm{p}<0.0025)$ and 278 versus $224 \mathrm{ml} /$ $1.73 \mathrm{~m}^{2}(\mathrm{p}<0.0005)$ respectively. Combining results from diabetic patients and controls revealed a positive correlation between kidney size and GFR ( $\mathrm{r}=$ $0.70, \mathrm{p}<0.001)$ and between kidney size and RPF $(\mathrm{r}=0.61, \mathrm{p}<0.001)$. Within the groups kidney size and RPF correlated significantly in the diabetics $(\mathrm{p}<$ 0.01 ) and the same was found for kidney size and GFR $(0.025<\mathrm{p}<0.05)$, while no correlations were found in the normal group. GFR and RPF correlated in the diabetics when evaluated separately $(\mathrm{r}=0.81$, $\mathrm{p}<0.001)$ and in the controls $(\mathrm{r}=0.73, \mathrm{p}<0.001)$. The previous and present data suggest that the mechanisms of the elevated GFR in insulin-dependent diabetics are enhanced RPF, increased transglomerular hydrostatic pressure gradient and increased glomerular ultrafiltration coefficient. The increased kidney size is probably the main cause of the above alterations in the GFR determinants.

Key words: Glomerular filtration rate, renal plasma flow, kidney size, insulin-dependent diabetes mellitus.

Mogensen and Andersen [1] found that the elevated glomerular filtration rate (GFR) in short-term insulin-dependent diabetes mellitus (IDD) was associ- ated with increased kidney size, measured on intravenous pyelograms taken with ureteric compression. Their study revealed a statistically significant positive correlation between kidney size and GFR as well as renal plasma flow (RPF). In addition kidney size and GFR were significantly reduced after 3 months of insulin treatment [2]. These findings led Mogensen and Andersen to suggest a causal connection between kidney size and kidney function in IDD [2]. No other studies in man concerning these two variables are available.

The aim of the present study was to expand the observations in man, using a new non-traumatic and non-invasive ultrasound technique for determination of kidney volume [3]. GFR and RPF were measured using classical constant infusion technique with $\mathrm{I}^{125}$-iothalamate and ${ }^{131} \mathrm{I}$-hippuran.

\section{Materials and Methods}

Thirteen male IDD patients (mean age 30 years) and fourteen normal male subjects (mean age 29 years) were investigated (Table 1). All the patients had been treated with insulin since diabetes was diagnosed, and all were taking insulin twice a day except patient 11 who was treated with a single injection in the morning. The patients were selected from the out-patient clinic without respect to their metabolic control. They were not admitted to hospital and no attempts were made to improve metabolic control prior to the investigation. All subjects were fully informed about the nature of the study before giving their consent. Clinical signs of diabetic microangiopathy were not present in any of the patients. At the time of the investigation they had no ketone bodies in the urine. None of the subjects was taking drugs other than insulin.

\section{Kidney Function}

GFR and RPF were measured using the classical steady state constant infusion technique with $\mathrm{I}^{125}$-iothalamate and ${ }^{131} \mathrm{I}$-hippuran respectively [4]. Measurements were carried out in the morning following an overnight fast. The diabetic patients had their last injection of insulin $24 \mathrm{~h}$ before the experiment. The subjects had one litre of tap water in the morning and were given $0.75 \mathrm{l} / \mathrm{h}$ during the clearance experiments. After 60 min constant infusion, 
Table 1. Pertinent clinical data for the thirteen insulin-dependent diabetic patients and the fourteen normal subjects

\begin{tabular}{|c|c|c|c|c|c|c|c|c|}
\hline \multicolumn{2}{|c|}{ Subject no. } & \multirow{2}{*}{$\begin{array}{l}\begin{array}{l}\text { Age } \\
\text { (years) }\end{array} \\
28\end{array}$} & \multirow{2}{*}{$\begin{array}{l}\begin{array}{l}\text { Duration of } \\
\text { diabetes } \\
\text { (years) }\end{array} \\
4\end{array}$} & \multirow{2}{*}{$\begin{array}{l}\text { Height } \\
\text { (cm) } \\
182\end{array}$} & \multirow{2}{*}{$\begin{array}{l}\begin{array}{l}\text { Weight } \\
\text { (kg) }\end{array} \\
70\end{array}$} & \multirow{2}{*}{$\begin{array}{l}\begin{array}{l}\text { Body surface } \\
\left(\mathrm{m}^{2}\right)\end{array} \\
1.88\end{array}$} & $\begin{array}{l}\text { Fasting blood } \\
\text { glucose } \\
(\mathrm{mmol} / \mathrm{l})\end{array}$ & \multirow{2}{*}{ 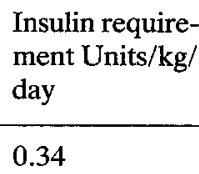 } \\
\hline \multirow{13}{*}{ 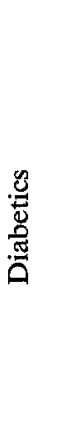 } & 1 & & & & & & 5.2 & \\
\hline & 2 & 27 & 4 & 192 & 80 & 2.09 & 15.0 & 0.45 \\
\hline & 3 & 28 & 3 & 178 & 69 & 1.86 & 9.1 & 0.58 \\
\hline & 4 & 21 & 3 & 185 & 74 & 1.97 & 11.1 & 0.63 \\
\hline & 5 & 22 & 3 & 186 & 72 & 1.92 & 15.8 & 0.69 \\
\hline & 6 & 35 & 7 & 181 & 67 & 1.86 & 12.5 & 0.58 \\
\hline & 7 & 33 & 6 & 188 & 80 & 2.05 & 9.0 & 0.52 \\
\hline & 8 & 26 & 0.3 & 189 & 73 & 1.99 & 9.9 & 0.22 \\
\hline & 9 & 36 & 0.2 & 169 & 63 & 1.70 & 6.6 & 0.25 \\
\hline & 10 & 37 & 0.4 & 179 & 72 & 1.89 & 5.0 & 0.27 \\
\hline & 11 & 35 & 0.2 & 178 & 60 & 1.75 & 5.4 & 0.16 \\
\hline & 12 & 28 & 0.3 & 186 & 61 & 1.82 & 3.7 & 0.46 \\
\hline & 13 & 32 & 0.2 & 190 & 73 & 2.00 & 7.7 & 0.38 \\
\hline \multicolumn{2}{|c|}{ mean } & 30 & 2.4 & 183 & 70 & 1.91 & 8.9 & 0.43 \\
\hline \multicolumn{2}{|c|}{$\mathrm{SD}$} & 5 & 2.3 & 6 & 6 & 0.11 & 3.9 & 0.17 \\
\hline \multirow{14}{*}{ 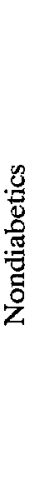 } & 1 & 29 & & 184 & 77 & 2.00 & 3.6 & \\
\hline & 2 & 33 & & 186 & 79 & 2.03 & 3.9 & \\
\hline & 3 & 28 & & 171 & 61 & 1.70 & 3.2 & \\
\hline & 4 & 26 & & 187 & 79 & 2.04 & 4.4 & \\
\hline & 5 & 26 & & 175 & 67 & 1.81 & 3.4 & \\
\hline & 6 & 26 & & 176 & 86 & 2.03 & 3.4 & \\
\hline & 7 & 26 & & 193 & 85 & 2.15 & 3.3 & \\
\hline & 8 & 35 & & 179 & 80 & 1.97 & 3.6 & \\
\hline & 9 & 33 & & 189 & 99 & 2.26 & 2.9 & \\
\hline & 10 & 31 & & 171 & 68 & 1.80 & 4.6 & \\
\hline & 11 & 34 & & 169 & 75 & 1.85 & 5.1 & \\
\hline & 12 & 25 & & 184 & 69 & 1.90 & 4.6 & \\
\hline & 13 & 25 & & 182 & 67 & 1.86 & 4.3 & \\
\hline & 14 & 25 & & 196 & 93 & 2.27 & 5.2 & \\
\hline \multicolumn{2}{|c|}{ mean } & 29 & & 182 & 78 & 1.98 & 4.0 & \\
\hline \multicolumn{2}{|c|}{$\mathrm{SD}$} & 4 & & 8 & 11 & 0.17 & 0.7 & \\
\hline
\end{tabular}

six consecutive clearance periods, each of $20 \mathrm{~min}$, were evaluated. The GFR and RPF values are given as the mean of all clearance periods. The values were corrected to $1.73 \mathrm{~m}^{2}$ body surface.

Thyroid uptake of radioactive iodide was blocked with potassium iodide $200 \mathrm{mg} /$ day for one week prior to the study.

\section{Kidney Size}

Determination of the renal volume was performed by ultrasound scanning as described by Rasmussen et al. [3]. The kidney volume was measured twice within one hour in each subject. The subjects were examined in the prone position. Previous ultrasound studies have revealed no significant difference in volumes of the two kidneys [3] and therefore only the right kidney was examined because of the easiest accessibility by ultrasound. The upper and lower poles of the kidney were outlined on transverse scans on a storage oscilloscope. The longitudinal axis was marked on the skin and a series of 10-13 equidistant transverse scans were registered perpendicular to this axis. The transverse scans were taken at $1 \mathrm{~cm}$ intervals. The kidney volumes were calculated based upon the areas of the transverse scans by means of a computerized programme [3].

To estimate the volumes of both kidneys the right kidney volume was multiplied by 2 . Values were corrected to $1.73 \mathrm{~m}^{2}$ body surface.

The accuracy (i. e. the closeness of the measured values to the true values) of the present applied ultrasound technique for volume determination has been investigated previously in a series of autopsy studies on 16 kidneys [3]. The difference between the calculated and the true kidney volume was $1 \mathrm{ml}$, expressed as the mean value. The 5 th and 95 th percentiles of this mean were $-21 \mathrm{ml}$ and $27 \mathrm{ml}$ respectively. The precision of the ultrasound method was $5.7 \%$ in the present study, expressed as the coefficient of variation on double determinations.

\section{Statistical Method}

The t-test for unpaired observations was used for statistical evaluation of results. 
Table 2. GFR, RPF (mean of measurements from six clearance periods) and kidney volume (mean of two measurements) in the thirteen insulin-dependent diabetic patients and the fourteen normal subjects $(\mathrm{CV}=$ coefficient of variation)

\begin{tabular}{|c|c|c|c|c|c|c|}
\hline $\begin{array}{l}\text { Subject } \\
\text { no. }\end{array}$ & $\begin{array}{l}\text { GFR } \\
\left(\mathrm{ml} / \mathrm{min} \times 1.73 \mathrm{~m}^{2}\right)\end{array}$ & $\begin{array}{l}\mathrm{CV} \\
(\%)\end{array}$ & $\begin{array}{l}\mathrm{RPF} \\
\left(\mathrm{ml} / \min \times 1.73 \mathrm{~m}^{2}\right)\end{array}$ & $\begin{array}{l}\mathrm{CV} \\
(\%)\end{array}$ & $\begin{array}{l}\text { Filtration- } \\
\text { fraction }\end{array}$ & $\begin{array}{l}\text { Kidney volume } \\
\left(\mathrm{ml} / 1.73 \mathrm{~m}^{2}\right)\end{array}$ \\
\hline \multirow{13}{*}{ 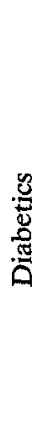 } & 151 & 4.1 & 684 & 3.9 & 0.22 & 314 \\
\hline & 122 & 4.0 & 476 & 5.9 & 0.26 & 257 \\
\hline & 160 & 3.3 & 709 & 4.2 & 0.23 & 251 \\
\hline & 157 & 5.1 & 690 & 4.8 & 0.23 & 320 \\
\hline & 140 & 5.0 & 690 & 4.8 & 0.20 & 300 \\
\hline & 153 & 2.0 & 590 & 4.7 & 0.26 & 273 \\
\hline & 142 & 3.9 & 639 & 4.0 & 0.22 & 280 \\
\hline & 180 & 1.7 & 691 & 4.0 & 0.26 & 303 \\
\hline & 125 & 3.9 & 600 & 4.7 & 0.21 & 314 \\
\hline & 129 & 5.4 & 553 & 5.1 & 0.23 & 247 \\
\hline & 113 & 5.8 & 456 & 4.9 & 0.25 & 207 \\
\hline & 160 & 3.7 & 771 & 4.1 & 0.21 & 298 \\
\hline & 142 & 6.2 & 599 & 5.9 & 0.24 & 254 \\
\hline mean & 144 & 4.2 & 627 & 4.7 & 0.23 & 278 \\
\hline SD & 19 & 1.3 & 93 & 0.7 & 0.02 & 34 \\
\hline \multirow{14}{*}{ 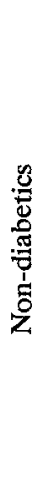 } & 114 & 5.4 & 590 & 4.4 & 0.19 & 207 \\
\hline & 118 & 5.5 & 487 & 6.6 & 0.24 & 291 \\
\hline & 93 & 8.3 & 405 & 7.9 & 0.23 & 252 \\
\hline & 119 & 2.5 & 547 & 4.5 & 0.22 & 243 \\
\hline & 123 & 7.5 & 657 & 8.8 & 0.19 & 248 \\
\hline & 109 & 6.3 & 506 & 6.0 & 0.21 & 239 \\
\hline & 139 & 3.1 & 559 & 3.0 & 0.25 & 231 \\
\hline & 90 & 4.7 & 372 & 5.2 & 0.24 & 181 \\
\hline & 109 & 7.3 & 436 & 8.9 & 0.25 & 191 \\
\hline & 122 & 1.4 & 597 & 4.8 & 0.20 & 242 \\
\hline & 110 & 2.4 & 497 & 2.3 & 0.22 & 242 \\
\hline & 105 & 4.4 & 521 & 3.0 & 0.20 & 160 \\
\hline & 118 & 4.9 & 568 & 4.7 & 0.21 & 214 \\
\hline & 109 & 3.1 & 582 & 4.2 & 0.19 & 194 \\
\hline mean & 113 & 4.8 & 523 & 5.3 & 0.22 & 224 \\
\hline SD & 12 & 2.1 & 79 & 2.1 & 0.02 & 34 \\
\hline $\mathrm{t}$-test & $\mathrm{p}<0.0005$ & & $\mathrm{p}<0.0025$ & NS & NS & $\mathrm{p}<0.0005$ \\
\hline
\end{tabular}

\section{Results}

Diabetic subjects demonstrated an elevated GFR $(+27 \%, \mathrm{p}<0.0005)$, an enlarged renal volume $(+$ $24 \%, \mathrm{p}<0.0005)$ and also an increased RPF $(+$ $20 \%, \mathrm{p}<0.0025$ ) (Table 2).

Using data from both diabetic patients and control subjects significant correlations between kidney size and GFR, and between kidney size and RPF were found $(r=0.70, p<0.001)$, and $(r=0.61, p<$ 0.001 ) (Fig. 1). When evaluating data from the groups separately kidney size and RPF correlated significantly in the diabetic patients $(r=0.69$, $\mathrm{p}<0.01)$ and the same was found for kidney size and GFR $(r=0.52,0.025<p<0.05)$, while no such correlations were found in the normal group (Fig. 1).
GFR and RPF were correlated in diabetic patients $(\mathrm{r}=0.81, \mathrm{p}<0.001)$ and in control subjects ( $\mathrm{r}=0.73, \mathrm{p}<0.001$ ) (Fig. 2). If GFR and RPF are expressed as $\mathrm{ml} / \mathrm{min}$ per $\mathrm{ml}$ estimated kidney volume, no significant differences between diabetic patients (GFR: $0.52 \pm 0.06$ (SD) $\mathrm{ml} / \mathrm{min} \times \mathrm{ml} \mathrm{kid-}$ ney volume, RPF: $2.26 \pm 0.25 \mathrm{ml} / \mathrm{min} \times \mathrm{ml} \mathrm{kidney}$ volume) and control subjects (GFR: $0.51 \pm 0.08 \mathrm{ml} /$ $\mathrm{min} \times \mathrm{ml} \mathrm{kidney} \mathrm{volume,} \mathrm{RPF:} 2.38 \pm 0.48 \mathrm{ml} / \mathrm{min}$ $\times \mathrm{ml}$ kidney volume) are found.

\section{Discussion}

The present study demonstrates a $24 \%$ increase in kidney volume in short-term IDD compared with non-diabetic controls in accordance with the original 

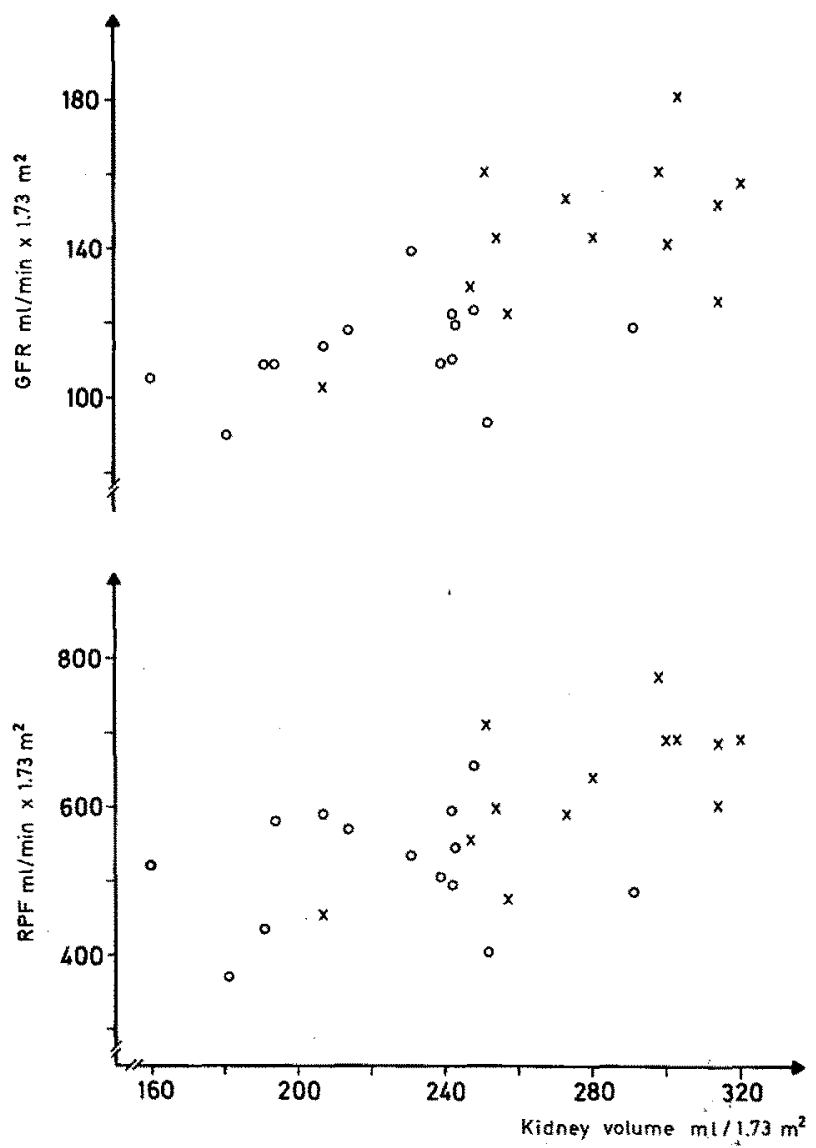

Fig. 1. Relation between glomerular filtration rate (GFR) and kidney volume and between renal plasma flow (RPF) and kidney volume in thirteen insulin-dependent diabetic patients and fourteen normal subjects. $x=$ Diabetics: GFR: $r=0.52(0.025<\mathrm{p}$ $<0.05)$ - RPF: $r=0.69(\mathrm{p}<0.01) .0=$ Controls: GFR: $r=$ 0.37 (n. s.) - RPF: $r=0.14$ (n. s.) report from Mogensen and Andersen [1]. The ultrasonic technique for kidney volume determination employed in our study has been shown to be very accurate [3] and reproducible - the coefficient of variation in this study was $5.7 \%$. Furthermore this procedure is non-invasive and non-traumatic and thus suitable for repeated investigations in the same patient under different conditions.

Increased kidney volume has also been found in streptozotocin diabetic rats $[5,6]$, where a significant correlation between blood glucose and kidney weight was found [5]. Seyer-Hansen has demonstrated that the renal growth in diabetic rats is predominantly due to hypertrophy (increased RNA/DNA ratio), while hyperplasia is less pronounced [6]. Furthermore, studies of compensatory kidney growth following reduction in renal mass also indicate that hypertrophy dominates the kidney growth [7]. Morphological studies of the kidney in diabetic rats as well as studies on compensatory hypertrophy in rats following renal mass reduction implicate the increase in tubular mass as the main cause of the increase in kidney weight [6, 7]. The demonstrated enlargement of the glomerulus in early diabetes in man and rats contributes very little $[8,9]$. The cause of the kidney enlargement in the two above mentioned conditions remains unknown. Increased work-load has been suggested in both conditions, but recent studies on kidney growth following reduction in renal mass do not support this hypothesis $[7,10]$. Such studies are lacking in diabetic animals. Alternatively kidney growth is attributed to a humoral substance that may control renal mass [7]. The elevation of growth hormone in IDD

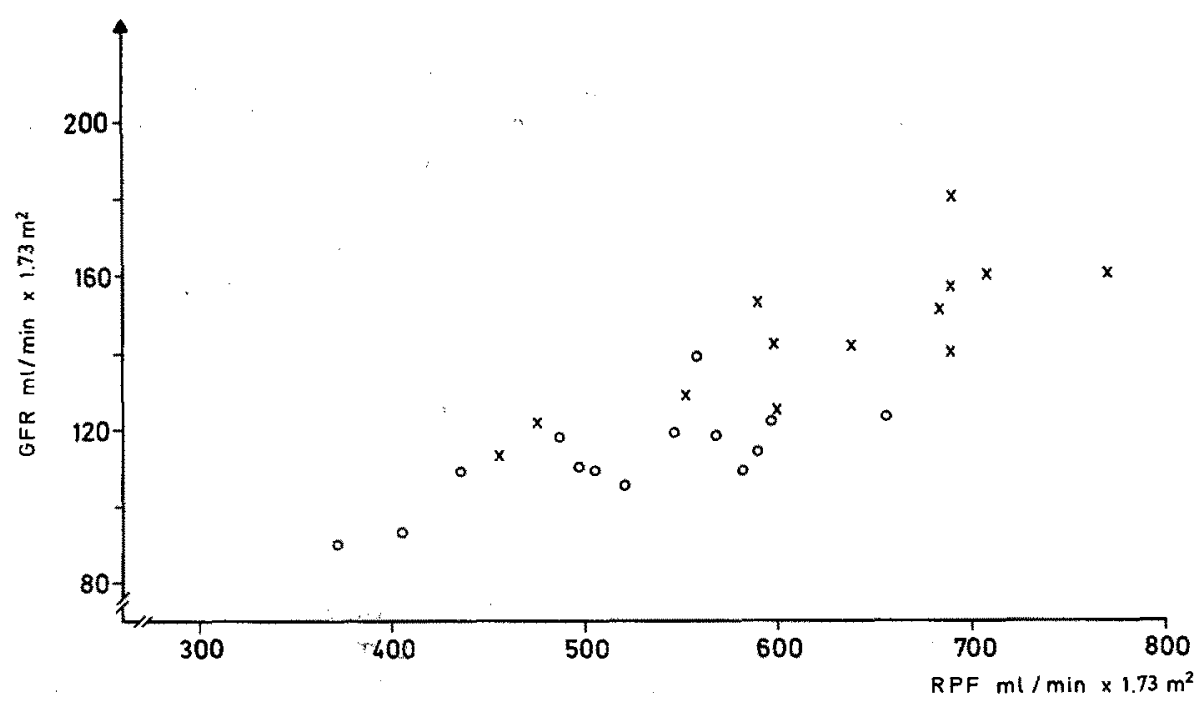

Fig. 2. Relation between glomerular filtration rate and renal plasma flow in thirteen insulin-dependent diabetic patients and fourteen normal subjects. $x=$ Diabetics: $\mathrm{r}=\mathbf{0 . 8 1}$ $(\mathrm{p}<0.001) . o=$ Controls: $r=0.73$ $(\mathrm{p}<0.01)$ 
Table 3. Comparison of GFR and RPF in IDD patients with different metabolic control (mean \pm SEM)

\begin{tabular}{lllllll}
\hline & $\begin{array}{l}\text { Number of } \\
\text { patients }\end{array}$ & $\begin{array}{l}\text { Duration of } \\
\text { diabetes (years })\end{array}$ & $\begin{array}{l}\mathrm{GFR} \\
\left(\mathrm{ml} / \mathrm{min} \times 1.73 \mathrm{~m}^{2}\right)\end{array}$ & $\begin{array}{l}\mathrm{RPF} \\
\left(\mathrm{ml} / \mathrm{min} \times 1.73 \mathrm{~m}^{2}\right)\end{array}$ & $\begin{array}{l}\text { Mean blood- } \\
\text { glucose }^{\mathrm{a}} \\
(\mathrm{mmol} / 1)\end{array}$ & $\begin{array}{l}\text { Urinary glucose } \\
\text { excretion }^{\mathrm{b}} \\
(\mathrm{g} / 24 \mathrm{~h})\end{array}$ \\
\hline $\begin{array}{l}\text { Parving } \\
\begin{array}{l}\text { et al. [16] } \\
\text { Present study }\end{array}\end{array}$ & 9 & $3 \pm 1$ & $133 \pm 5$ & $530 \pm 21$ & $9.4 \pm 0.9$ & $15 \pm 4$ \\
$\begin{array}{l}\text { Christiansen } \\
\text { et al. [13] }\end{array}$ & 13 & $2 \pm 1$ & $144 \pm 5$ & $627 \pm 26^{\mathrm{c}}$ & $13.0 \pm 1.1^{\mathrm{c}}$ & $36 \pm 8^{\mathrm{c}}$ \\
\hline
\end{tabular}

a Mean of postprandial blood glucose measurements in the morning within the last year

b Mean of 24-hour glucose excretion measurements within the last year

c Significantly elevated $(p<0.05)$ compared with Parving et al. [16]

[11] may, as suggested by Mogensen and Andersen [2], contribute to the kidney enlargement. Acromegalic patients have increased growth hormone, kidney size, GFR and RPF [12].

In the present study GFR as well as RPF were found significantly elevated in the diabetic patients compared to the controls. Recently we found GFR and RPF elevated to nearly the same extent in another group of IDD patients comparable to the present group of patients - also with respect to metabolic control [13], (Table 3). Elevated GFR is a well established feature in short-term IDD [4, 14]. The results regarding $R P F$ in insulin-dependent juvenile diabetic patients with duration of diabetes less than 12 years have been conflicting. Ditzel and Junker found a reduced RPF [14]. The RPF was measured in the morning after the patients had received their usual insulin dose at $0700 \mathrm{~h}$. Recent studies have demonstrated that insulin reduces RPF in short-term IDD [13, 15]. Mogensen [4] demonstrated a significantly elevated RPF $(+10 \%)$ in 28 short-term diabetic Patients compared with 31 age and sex matched normal subjects. Mogensen [1] obtained the same RPF elevation $(+10 \%)$ in a larger study dealing with 12 diabetic patients and 12 normal subjects, but this did not reach statistical significance. Compilation of the RPF values in the two investigations by Mogensen clearly shows a significantly elevated RPF in his short-term diabetic patients.

In a recent study dealing with the effect of glucagon on kidney function in IDD patients we reported normal RPF values [16]. The patients in that study were selected among out-patients usually showing excellent metabolic control. They were admitted to hospital 10-14 days prior to the clearance studies for further improvement of their metabolic control. No such attempts were made in the present or in our previous study [13]. Table 3 shows that mean bloodglucose and 24-hour urinary glucose excretion were significantly lower in the IDD patients with normal
RPF compared with the two other groups. This suggests that strict metabolic control decreases GFR and RPF in agreement with previous findings [17].

The present study revealed a positive correlation between GFR and RPF in both groups (Fig. 2). Studies of renal haemodynamics have consistently demonstrated a close relationship between GFR and RPF as reviewed by Brenner and Humes [18]. One has to bear in mind, however, that errors in urine collection will affect GFR and RPF and thus induce a tendency to a false correlation in our studies. This influence has, however, been considerably reduced using results from six clearance periods. Furthermore the coefficients of variation for GFR and RPF measurements were below $5.3 \%$ (Table 2).

A significant positive correlation between kidney size and GFR and between kidney size and RPF was found in the present investigation. Mogensen and Andersen [1] found this relationship to be present both in the diabetic and normal groups. The lack of correlation in our normal group cannot be explained by differences in kidney function tests applied in the two studies since they were identical. The accuracy and reproducibility of the different methods for kidney size measurements are fully comparable $[3,19]$. Thus, the most likely explanation for the slightly different results is the limited number of subjects and the relatively small scatter around mean values. Reduction in kidney size and GFR has been demonstrated after 3 months of insulin treatment in newly diagnosed IDD [2 ]. These findings are compatible with a causal relationship between kidney size and GFR [2]. The only way increased kidney size can affect GFR is by altering one of the well defined determinants of GFR or one of the factors which control each of these [18]. These determinants include: a) RPF, determined by afferent and efferent arteriolar resistence; b) Transglomerular pressure, as determined by hydrostatic pressure favouring filtration and oncotic pressure opposing filtration; c) Kf (ultrafiltration coefficient), which is determined by 
the water permeability of the glomerular capillary and its surface area available for filtration.

The present and the previous findings $[1,2,4]$ of an increased kidney size and elevated RPF and a significant positive correlation between them, may suggest that kidney growth in some way stimulates an increase in RPF, and thereby GFR. Tucker and Blantz [20] found a highly significant positive correlation between kidney weight and RPF in the mature growing rat, and demonstrated that this flow increase was due to parallel reductions in afferent and efferent resistances. They suggested that this decrease in arteriolar resistance presumably was a result of increased arteriolar diameter with growth of the kidney. It is conceiveable that the same alterations take place during growth of the diabetic kidney.

There is no available information regarding the transglomerular hydrostatic pressure gradient in human diabetes. In 1978, Hostetter et al. [21] carried out the first detailed study of glomerular dynamics in streptozotocin diabetic rats. They found increased kidney weight, elevated single nephron GFR, increased RPF, increased transglomerular hydrostatic pressure gradient and increased Kf. Recently, we have confirmed these observations in streptozotocin diabetic rats (Jensen et al., unpublished observations).

The above mentioned increase in $\mathrm{Kf}$ can be due to increased water permeability of the glomerular capillary and/or enlarged surface area available for filtration. Seyer-Hansen and Hansen [22] have shown enlargement of the glomerular volume in streptozotocin diabetic rats. Østerby and her colleagues [23] have demonstrated an increase of the glomeruli and an enlargement of the glomerular filtration surface area in newly diagnosed and shortterm IDD patients. Previous studies in IDD patients have not revealed any changes in the size-selective permeability of the glomerular membrane $[4,24]$. Therefore we suggest that increased surface area available for filtration is the main cause of the elevated Kf.

The elevated GFR in diabetics are due to increased RPF, elevated transglomerular hydrostatic pressure gradient and increased glomerular ultrafiltration coefficient. The contribution from each of these determinants of GFR remains to be elucidated.

\section{References}

1. Mogensen CE, Andersen MJF (1973) Increased kidney size and glomerular filtration rate in early juvenile diabetes. Diabetes 22: 706-712

2. Mogensen CE, Andersen MJF (1975) Increased kidney size and glomerular filtration rate in untreated juvenile diabetics: Normalization by insulin-treatment. Diabetologia 11: 221-224

3. Rasmussen SN, Haase L, Kjeldsen H, Hancke S (1978) Deter- mination of renal volume by ultrasound scanning. JCU 6 : 160-164

4. Mogensen CE (1972) Kidney function and glomerular permeability to macromolecules in juvenile diabetes. Dan Med Bull 19 [Suppl 3]: 1-40

5. Seyer-Hansen K (1977) Renal hypertrophy in experimental diabetes: Relation to severity of diabetes. Diabetologia 13: 141-143

6. Seyer-Hansen K (1978) Renal hypertrophy in experimental diabetes: A comparison to compensatory hypertrophy. Diabetologia 14: 325-328

7. Hayslett JP (1979) Functional adaptation to reduction in renal mass. Physiol Rev 59: 137-164

8. Østerby R, Gundersen HJG (1975) Glomerular size and structure in diabetes mellitus. I. Early abnormalities. Diabetologia 11: 225-229

9. Seyer-Hansen K, Hansen J, Gundersen HJG (1980) Renal hypertrophy in experimental diabetes. A morphometric study. Diabetologia 18: 501-505

10. Katz AI, Toback G, Lindheimer MD (1976) Independence of onset of compensatory kidney growth from changes in renal function. Am J Physiol 230: 1067-1071

11. Hansen AaP (1972) Serum growth hormone patterns in juvenile diabetes. Dan Med Bull 19 [Suppl 1]: 1-31

12. Falkheden T, Sjögren B (1964) Extracellular fluid volume and renal function in pituitary insufficiency and acromegaly. Acta Endocrinol (Kbh) 46: 80-86

13. Christiansen JS, Frandsen M, Parving H-H (1981) The effect of intravenous insulin infusion on kidney function in insulindependent diabetes mellitus. Diabetologia 20: 199-204

14. Ditzel J, Junker K (1972) Abnormal glomerular filtration rate, renal plasma flow and renal protein excretion in recent and short-term diabetics. Br Med J II: 13-19

15. Mogensen CE, Christensen NJ, Gundersen HJG (1978) The acute effect of insulin on renal hemodynamics and protein excretion in diabetes. Diabetologia 15: 153-157

16. Parving $\mathrm{H}-\mathrm{H}$, Christiansen JS, Noer $\mathrm{I}$, Tronier B, Mogensen CE (1980) The effect of glucagon infusion on kidney function in short-term insulin-dependent juvenile diabetes. Diabetologia 19: $350-354$

17. Christiansen JS, Parving H-H, Gammelgaard J, Holm HH, Svendsen PAa (1979) Kidney function and kidney size in newly diagnosed insulin-dependent diabetics before and during initial insulin therapy. Excerpta Med 481: 202

18. Brenner BM, Humes HD (1977) Mechanisms of glomerular ultrafiltration. N Engl J Med 297: 148-154

19. Lundin H (1967) Radiologic estimation of kidney weight. Acta Radiol [Diagn] 6: 561-574

20. Tucker BJ, Blantz EC (1977) Factors determining superficial nephron filtration in the mature growing rat. Am J Physiol 232: F97-F104

21. Hostetter TH, Troy JL, Brenner BM (1978) Glomerular dynamics in rats with diabetes mellitus (abstract). Kidney Int 14: 725

22. Seyer-Hansen K, Hansen $J$ (1979) Morphometric analysis of kidney hypertrophy in diabetic rats. Excerpta Med 481: 213

23. Kroustrup JG, Gundersen HJG, Østerby R (1977) Glomerular size and structure in diabetes mellitus. III. Early enlargement of the capillary surface. Diabetologia 13: 207-210.

24. Parving H-H, Rutili F, Granath K, Noer I, Deckert T, Lyngsøe J, Lassen NA (1979) Effect of metabolic regulation on renal leakeness to Dextran molecules in short-term insulin-dependent diabetics. Diabetologia 17: 157-160

Received: September 10, 1980

Jens Sandahl Christiansen, M.D.

Steno Mernorial Hospital

DK-2820 Gentofte

Denmark 